\title{
AGENTES COMUNITÁRIOS DE SAÚDE NA ATENÇÃO PRIMÁRIA NO BRASIL: MULTIPLICIDADE DE ATIVIDADES E FRAGILIZAÇÃO DA FORMAÇÃO
}

\author{
COMMUNITY HEALTH AGENTS IN PRIMARY ATTENTION IN BRAZIL: \\ MULTIPLICITY OF ACTIVITIES AND FRAGILIZATION OF TRAINING
}

AGENTES COMUNITARIOS DE SALUD EN LA ATENCIÓN PRIMARIA EN BRASIL:

MULTIPLICIDAD DE ACTIVIDADES Y FRAGILIZACIÓN DE LA FORMACIÓN

\author{
Jania Lurdes Pires Samudio ${ }^{1}$ \\ Letícia Carneiro Brant ${ }^{2}$ \\ Ana Clara de Freitas Dias Costa Martins ${ }^{3}$ \\ Maria Aparecida Vieira ${ }^{4}$ \\ Cristina Andrade Sampaio 5
}

Resumo O estudo teve como objetivo avaliar, mediante revisão integrativa, o conhecimento produzido na literatura acerca das atividades desempenhadas pelos agentes comunitários de saúde no Brasil e em outros países. A busca de dados, realizada no período de 2010 a 2014, abrangeu: Portal de Periódicos da Coordenação de Aperfeiçoamento de Pessoal de Nível Superior; biblioteca eletrônica Scientific Electronic Library Online; Literatura Latino-Americana e do Caribe em Ciências da Saúde; Medical Literature Analysis and Retrieval System On-line e US National Library of Medicine National Institutes of Health. Dos 240 estudos identificados, 27 foram incluídos nesta revisão. A literatura evidencia as funções que os agentes comunitários de saúde exercem, em variedade de ações em diversos contextos geográficos e culturais. $\mathrm{O}$ agente tem diferentes inserções no mercado de trabalho e vivencia fragilidades, oriundas de contextos socioculturais da comunidade, da necessidade de maior reconhecimento do sistema de saúde e da equipe. Sua posição entre a comunidade e a equipe de saúde é estratégica, contribuindo para a saúde da comunidade. Deve-se proporcionar formação propícia à sua atuação e possibilitar o acesso à educação permanente, além de se promoverem recursos para maior valorização da equipe de saúde em sua relação com a sociedade.

Palavras-chave agente comunitário de saúde; atenção primária à saúde; políticas públicas; Estratégia Saúde da Família.
Abstract The study had as objective to avaliate, through an integrative review of the literature, the produced knowledge about the activities carried out by community health agents in Brazil and some other countries. The search of data has included: Journals of Higher Education Personnel Improvement Coordination Website; Scientific Electronic Library Online; Latin American and Caribbean Health Sciences Literature; Medical Literature Analysis and Retrieval System Online and US National Library of Medicine National Institutes of Health, and has happened from 2010 to 2014. Of the 240 studies identified, 27 were included in this review. The literature highlights the functions that the Community Health Agents have been promoting in a variety of actions in different geographical and cultural contexts. The Community Health Agent has different insertions in the labor market experiences and the fragilities that come from the communities' socio-cultural contexts, to the need of greater recognition of the health system and the health staff. Its position, between the community and the health staff, is strategic and contributes to the health of the community. Therefore, it should be given proper training to their performance and access to lifelong education, resources and a greater appreciation of the health staff with the society.

Keywords community health agents; primary health care; public policy; family health strategy. 


\section{Introdução}

Agentes comunitários de saúde (ACSs) são, conforme a Organização Mundial da Saúde (OMS), profissionais selecionados e residentes nas comunidades em que trabalham, responsáveis por atividades de saúde, de acordo com o que foi preestabelecido pelos sistemas de saúde (World Health Organization, 1989). São profissionais estratégicos na atenção primária à saúde (APS), influenciando na criação e na manutenção de comportamentos saudáveis onde há poucos profissionais ou o acesso ao serviço de saúde é difícil, em razão de pouca oferta ou distribuição díspar entre a população rica e a pobre (Perry e Zulliger, 2012). Caracterizam-se como categoria diversificada de profissionais e recebem nomeações de acordo com o país no qual estão inseridos - colaborador voluntário, na Guatemala; brigadista, na Nicarágua; activista, em Moçambique; e basic health worker, na Índia (World Health Organization, 2007). Independentemente da nacionalidade, será aqui denominado agente comunitário de saúde.

Nos anos 1920, em Ding Xian (China), os primeiros ACSs, agricultores analfabetos, recebiam três meses de treinamento e trabalhavam meio expediente como profissionais de saúde. Registravam casos de nascimento e morte; vacinavam contra varíola e outras doenças; orientavam sobre limpeza de poços e cuidados médicos básicos. Conhecidos como médicos descalços (MDs), na década de 1970 somavam um milhão, servindo a 800 milhões de pessoas na área rural da República Popular da China (Perry e Zulliger, 2012).

Após 1960, o modelo médico ocidental de assistência às populações pobres/ rurais tornou-se insuficiente, e o paradigma dos MDs foi seguido na Indonésia, Índia, Tanzânia, Venezuela, Honduras e Guatemala. Somou-se às propostas do Conselho Mundial de Igrejas, com sede em Genebra, referentes à saúde como prevenção, equidade, participação comunitária, trabalho intersetorial, descentralização dos serviços de saúde para as periferias, uso de tecnologias apropriadas e prestação de serviços por uma equipe multidisciplinar, incluindo o ACS. Sua atuação orientou a definição do papel do agente comunitário na prestação de cuidados na APS, ocorrida em 1978, na Conferência Internacional sobre Cuidados de Saúde Primários, em Alma-Ata (Perry, 2013).

Em 1970 e 1980, programas de ACS proliferaram na Indonésia, Índia, Nepal, Zimbabwe, Tanzânia, Malawi, Moçambique, Nicarágua, Honduras, Bolívia, Brasil, Cuba, Equador e Venezuela (Perry, 2013; Queirós, 2015).

O bem-sucedido programa de ACS do Brasil, da década de 1980, com o gradual avanço dos serviços de APS, levou melhorias à população (Perry, 2013). O Ministério da Saúde/Fundação Nacional de Saúde implantou mudanças, com o Programa de Agentes Comunitários de Saúde (Pacs) em 1991, inicialmente no Norte e no Nordeste do Brasil, em áreas periféricas urbanas e rurais, a partir de experiências exitosas no Ceará, realizadas em 1987. Objetivava garantir, emergencialmente, assistência básica à população sem acesso a condutas mé- 
dicas. A escassez da assistência médico-sanitária levou os ACSs a realizarem outras atividades (Mendes, 2012; Giovanella e Mendonça, 2008).

Em 1994, implantou-se, pelo Ministério da Saúde, o Programa de Saúde da Família (PSF). Pela portaria n. 648/GM-2006 (Brasil, 2006a), instituiu-se a Política Nacional de Atenção Básica no Brasil, revisando diretrizes e normas para a organização da atenção básica para o PSF e para o Pacs, cuja adequada implementação é elemento estratégico para a consolidação do Sistema Único de Saúde (SUS). Essa portaria definiu as atribuições do ACS, ampliadas, em 2011, pela publicação da portaria n. 2.488 (Brasil, 2011).

A atuação do ACS tem despertado interesse no mundo científico. Há semelhanças e diferenças quanto às atividades realizadas e à inserção no mercado de trabalho em saúde, no Brasil e em outros países. O estudo aqui apresentado procurou descrever o conhecimento produzido na literatura acerca das atividades realizadas pelos ACSs no Brasil e em outros países que contam com esse profissional em seu sistema de saúde.

\section{Revisão integrativa: elementos metodológicos}

O estudo que deu origem a este artigo propôs-se a fazer uma revisão integrativa de literatura, com base em ampla análise de publicações, para obter dados e conclusões sobre determinada temática (Polit, Beck e Hungler, 2011). Realizou-se em seis passos (Mendes et al., 2008), começando pela demarcação das questões norteadoras: quais atividades realizadas pelos ACSs na APS no Brasil e no mundo? Qual sua inserção no trabalho em saúde? Depois selecionaram-se descritores no vocabulário controlado de descritores em ciências da saúde (DeCSs), utilizados de forma isolada ou combinada na estratégia de busca (Quadro 1).

Em seguida, efetuou-se a busca, de outubro a dezembro de 2014, em inglês, espanhol e português, nas bases de dados: biblioteca eletrônica Scientific Electronic Library Online (SciELO), Literatura Latino-Americana e do Caribe em Ciências da Saúde (Lilacs), Medical Literature Analysis and Retrieval System On-line (Medline), US National Library of Medicine National Institutes of Health (PubMed) e Portal de Periódicos da Coordenação de Aperfeiçoamento de Pessoal de Nível Superior (Portal Capes). Obtiveram-se 77 artigos na base de dados Medline; 65 na Pubmed; 57 no Portal Capes; 31 na Lilacs e dez na SciELO, totalizando 240 artigos. Realizado isso, efetuou-se: leitura seletiva a partir de título e resumo, selecionando-se 52; leitura crítica e integral, partindo dos critérios de inclusão: estudos na íntegra, acessíveis e publicados nos idiomas citados, que respondessem ao objetivo proposto, publicados no período de 2010 a 2016; exclusão de publicações duplicadas (111), presentes em mais de uma base e sem pertinência com a temática (102); análise de dois pesquisadores - os artigos discordantes foram analisados por um terceiro pesquisador; no final do procedimento, seleção de 27 artigos: 16 em português e 11 em inglês. 
Quadro 1

\begin{tabular}{|c|c|c|c|}
\hline \multicolumn{4}{|c|}{ Fontes de informação, expressões de busca e resultados dos documentos identificados, 2015} \\
\hline Fontes & Expressão de busca & $\begin{array}{l}\text { Documentos } \\
\text { identificados }\end{array}$ & $\begin{array}{l}\text { Documentos } \\
\text { selecionados }\end{array}$ \\
\hline SciELO & $\begin{array}{l}\text { "agentes comunitários de saúde" OR "auxiliares de saúde } \\
\text { comunitária" "atenção primária à saúde" OR "atenção básica" } \\
\text { OR "prática profissional" }\end{array}$ & 10 & 06 \\
\hline Lilacs & $\begin{array}{l}\text { "agentes comunitários de saúde" OR "auxiliares de saúde } \\
\text { comunitária" "atenção primária à saúde" OR "atenção básica" } \\
\text { OR "prática profissional" }\end{array}$ & 31 & 09 \\
\hline Medline & $\begin{array}{l}\text { "agentes comunitários de saúde" OR "auxiliares de saúde } \\
\text { comunitária" "atenção primária à saúde" OR “atenção básica" } \\
\text { OR "prática profissional" }\end{array}$ & 77 & 06 \\
\hline Capes & $\begin{array}{l}\text { "community health workers" AND "primary health care" AND } \\
\text { "professional practice" }\end{array}$ & 57 & 02 \\
\hline PubMed & $\begin{array}{l}\text { "community health workers" AND "primary health care" AND } \\
\text { "professional practice" }\end{array}$ & 65 & 04 \\
\hline Total & & 240 & 27 \\
\hline
\end{tabular}

Fonte: Os autores.

No terceiro passo, selecionaram-se informações relativas ao assunto e extraíram-se dados: publicação, autoria, local, ano de publicação, base de indexação, local do estudo, objetivo, desenho metodológico, principais resultados. Com isso, reuniram-se as informações sintetizadas numa planilha (Quadro 2), para o que foram lidas, na íntegra, e analisadas. No quarto, no quinto e no sexto passos, analisaram-se publicações, sua interpretação, síntese e apresentação da revisão.

Quadro 2

\begin{tabular}{|c|c|c|c|c|c|c|}
\hline \multicolumn{7}{|c|}{ Descrição dos estudos publicados entre 2010 e 2014 relacionados às ações realizadas pelo ACS na APS, 2015} \\
\hline Título do artigo & $\begin{array}{l}\text { Periódico } \\
\text { e ano de } \\
\text { publicação }\end{array}$ & Autores & Objetivo do estudo & $\begin{array}{l}\text { Tipo de } \\
\text { estudo }\end{array}$ & $\begin{array}{c}\text { Estado/ } \\
\text { Localidade } \\
\text { e país da } \\
\text { publicação }\end{array}$ & $\begin{array}{c}\text { Atividades realizadas } \\
\text { pelo ACS }\end{array}$ \\
\hline $\begin{array}{l}\text { Incorporação das } \\
\text { atividades de controle } \\
\text { da dengue pelo agente } \\
\text { comunitário de saúde }\end{array}$ & $\begin{array}{c}\text { Revista de } \\
\text { Saúde Pública } \\
\text { (2014) }\end{array}$ & Cazola et al. & $\begin{array}{l}\text { Avaliar o desempenho do } \\
\text { ACS após incorporação } \\
\text { do controle da dengue às } \\
\text { suas atribuições. }\end{array}$ & $\begin{array}{l}\text { Estudo } \\
\text { quantitativo }\end{array}$ & $\begin{array}{l}\text { São Paulo } \\
\text { (Brasil) }\end{array}$ & $\begin{array}{l}\text { Realiza agendamento de } \\
\text { consulta para mulheres } \\
\text { com atraso menstrual, } \\
\text { identificadas na visita } \\
\text { domiciliar; orienta e } \\
\text { acompanham pré-natal, } \\
\text { esquema vacinal de crianças } \\
\text { menores de um ano, } \\
\text { hipertensos e controle da } \\
\text { dengue. }\end{array}$ \\
\hline
\end{tabular}




\section{Continuação - Quadro 2}

\begin{tabular}{|c|c|c|c|c|c|c|}
\hline \multicolumn{7}{|c|}{ Descrição dos estudos publicados entre 2010 e 2014 relacionados às ações realizadas pelo ACS na APS, 2015} \\
\hline Título do artigo & $\begin{array}{l}\text { Periódico } \\
\text { e ano de } \\
\text { publicação }\end{array}$ & Autores & Objetivo do estudo & $\begin{array}{l}\text { Tipo de } \\
\text { estudo }\end{array}$ & $\begin{array}{l}\text { Estado/ } \\
\text { Localidade } \\
\text { e país da } \\
\text { publicação }\end{array}$ & $\begin{array}{c}\text { Atividades realizadas } \\
\text { pelo ACS }\end{array}$ \\
\hline $\begin{array}{l}\text { Auxiliares } \\
\text { odontológicos contra } \\
\text { agentes comunitários } \\
\text { de saúde: semelhanças } \\
\text { e contrastes }\end{array}$ & $\begin{array}{l}\text { Revista de } \\
\text { Odontologia } \\
\text { da Unesp } \\
\text { (2013) }\end{array}$ & $\begin{array}{l}\text { Costa e } \\
\text { Araújo }\end{array}$ & $\begin{array}{l}\text { Analisar atribuições dos } \\
\text { auxiliares de cirurgiões- } \\
\text { dentistas e dos ACSs na } \\
\text { utilização de serviços e na } \\
\text { formação, identificando } \\
\text { similaridades e contrastes } \\
\text { entre os profissionais. }\end{array}$ & $\begin{array}{l}\text { Estudo } \\
\text { quantitativo }\end{array}$ & $\begin{array}{l}\text { São Paulo } \\
\text { (Brasil) }\end{array}$ & $\begin{array}{l}\text { Efetua visita domiciliar e } \\
\text { cadastro de famílias; identifica } \\
\text { condições de saúde do território } \\
\text { e risco das famílias; promove } \\
\text { vigilância à saúde, reflexões do } \\
\text { trabalho em equipe, educação e } \\
\text { mobilidade comunitária. }\end{array}$ \\
\hline $\begin{array}{l}\text { Articulação das ações e } \\
\text { interação dos agentes } \\
\text { comunitários de saúde } \\
\text { na equipe de Saúde da } \\
\text { Família }\end{array}$ & $\begin{array}{c}\text { Revista da } \\
\text { Escola de } \\
\text { Enfermagem } \\
\text { da USP (2012) }\end{array}$ & $\begin{array}{l}\text { Sakata e } \\
\text { Mishima }\end{array}$ & $\begin{array}{l}\text { Compreender as relações } \\
\text { sociais entre o ACS e a } \\
\text { equipe de saúde da família } \\
\text { por meio da articulação } \\
\text { de ações e interação entre } \\
\text { trabalhadores. }\end{array}$ & $\begin{array}{l}\text { Estudo } \\
\text { quantitativo }\end{array}$ & $\begin{array}{l}\text { São Paulo } \\
\text { (Brasil) }\end{array}$ & $\begin{array}{l}\text { Reforça os aspectos técnico- } \\
\text { operacionais do trabalho, } \\
\text { desenvolve ações para } \\
\text { agilizá-lo em interação com } \\
\text { os trabalhadores, construindo } \\
\text { planos assistenciais em comum. }\end{array}$ \\
\hline $\begin{array}{l}\text { Agente comunitário de } \\
\text { saúde: um novo ator } \\
\text { no cenário da saúde } \\
\text { do Brasil }\end{array}$ & $\begin{array}{c}\text { Physis: Revista } \\
\text { de Saúde } \\
\text { Coletiva (2011) }\end{array}$ & $\begin{array}{c}\text { Filgueiras e } \\
\text { Silva }\end{array}$ & $\begin{array}{l}\text { Correlacionar } \\
\text { facilitadores e limitadores } \\
\text { das atividades } \\
\text { designadas aos ACSs. }\end{array}$ & $\begin{array}{l}\text { Estudo } \\
\text { qualitativo }\end{array}$ & $\begin{array}{l}\text { Rio de Janeiro } \\
\text { (Brasil) }\end{array}$ & $\begin{array}{l}\text { Realiza visita domiciliar, } \\
\text { espaço onde acontecem ações } \\
\text { educativas e preventivas; } \\
\text { ocupa lugar de elo entre } \\
\text { equipe e família. }\end{array}$ \\
\hline $\begin{array}{l}\text { Funções do agente } \\
\text { comunitário de saúde } \\
\text { no trabalho com redes } \\
\text { sociais }\end{array}$ & $\begin{array}{c}\text { Estudos de } \\
\text { Psicologia } \\
\text { (2014) }\end{array}$ & $\begin{array}{c}\text { Pinheiro e } \\
\text { Guanaes- } \\
\text { Lorenzi }\end{array}$ & $\begin{array}{l}\text { Apresentar como os ACSs } \\
\text { significam sua prática } \\
\text { com redes sociais, dando } \\
\text { visibilidade às funções que } \\
\text { exercem em seu trabalho. }\end{array}$ & $\begin{array}{l}\text { Estudo } \\
\text { qualitativo }\end{array}$ & $\begin{array}{l}\text { Rio Grande do } \\
\text { Norte (Brasil) }\end{array}$ & $\begin{array}{l}\text { Exerce as funções principais } \\
\text { de articulador da rede para } \\
\text { o cuidado e de mediador em } \\
\text { situações de conflito. }\end{array}$ \\
\hline $\begin{array}{l}\text { Agente comunitário de } \\
\text { saúde no controle da } \\
\text { tuberculose na atenção } \\
\text { primária à saúde }\end{array}$ & $\begin{array}{c}\text { Acta Paulista } \\
\text { de Enfermagem } \\
\text { (2012) }\end{array}$ & $\begin{array}{l}\text { Crispim } \\
\text { et al. }\end{array}$ & $\begin{array}{l}\text { Avaliar o desempenho } \\
\text { do ACS no controle da TB } \\
\text { em áreas assistidas pela } \\
\text { Estratégia Saúde da Família } \\
\text { (ESF), estabelecendo } \\
\text { uma análise comparativa } \\
\text { com os ACSs inscritos nas } \\
\text { unidades básicas de saúde } \\
\text { tradicionais. }\end{array}$ & $\begin{array}{l}\text { Estudo } \\
\text { quantitativo }\end{array}$ & $\begin{array}{l}\text { São Paulo } \\
\text { (Brasil) }\end{array}$ & $\begin{array}{l}\text { Verifica-se fragilidade dos } \\
\text { ACSs em incorporar as ações } \\
\text { de controle da TB nas distintas } \\
\text { modalidades de APS. }\end{array}$ \\
\hline $\begin{array}{l}\text { Atuação dos agentes } \\
\text { comunitários de } \\
\text { saúde na Estratégia } \\
\text { Saúde da Família }\end{array}$ & $\begin{array}{c}\text { Cogitare } \\
\text { Enfermagem } \\
\text { (2012) }\end{array}$ & Silva et al. & $\begin{array}{l}\text { Caracterizar a atuação } \\
\text { dos ACSs de unidades } \\
\text { básicas de saúde da } \\
\text { família de Três Lagoas } \\
\text { (MS). }\end{array}$ & $\begin{array}{l}\text { Estudo } \\
\text { quantitativo }\end{array}$ & $\begin{array}{l}\text { Paraná } \\
\text { (Brasil) }\end{array}$ & $\begin{array}{l}\text { Os ACSs reconhecem suas } \\
\text { atribuições e desempenham } \\
\text { atividades nelas não incluídas, } \\
\text { como entrega de medicamentos, } \\
\text { receitas, encaminhamento e } \\
\text { solicitação de agendamentos; } \\
\text { atividades administrativas e } \\
\text { apoio emocional. }\end{array}$ \\
\hline
\end{tabular}


Continuação - Quadro 2

\begin{tabular}{|c|c|c|c|c|c|c|}
\hline \multicolumn{7}{|c|}{ Descrição dos estudos publicados entre 2010 e 2014 relacionados às ações realizadas pelo ACS na APS, 2015} \\
\hline Título do artigo & $\begin{array}{l}\text { Periódico } \\
\text { e ano de } \\
\text { publicação }\end{array}$ & Autores & Objetivo do estudo & $\begin{array}{l}\text { Tipo de } \\
\text { estudo }\end{array}$ & $\begin{array}{l}\text { Estado/ } \\
\text { Localidade } \\
\text { e país da } \\
\text { publicação }\end{array}$ & $\begin{array}{c}\text { Atividades realizadas } \\
\text { pelo ACS }\end{array}$ \\
\hline $\begin{array}{l}\text { A construção } \\
\text { do cuidado: o } \\
\text { atendimento às } \\
\text { situações de violência } \\
\text { doméstica por } \\
\text { equipes de saúde da } \\
\text { família }\end{array}$ & $\begin{array}{c}\text { Saúde e } \\
\text { Sociedade } \\
\text { (2014) }\end{array}$ & $\begin{array}{l}\text { Moreira } \\
\text { et al. }\end{array}$ & $\begin{array}{l}\text { Analisar as estratégias } \\
\text { de cuidado construídas } \\
\text { por equipes de } \\
\text { saúde da família ante } \\
\text { situações de violência } \\
\text { doméstica. }\end{array}$ & $\begin{array}{l}\text { Estudo } \\
\text { qualitativo }\end{array}$ & $\begin{array}{l}\text { São Paulo } \\
\text { (Brasil) }\end{array}$ & $\begin{array}{l}\text { O ACS realiza visita } \\
\text { domiciliar; há monitoramento } \\
\text { dos casos e dos efeitos das } \\
\text { intervenções da equipe; é } \\
\text { 'mediador de conflito' entre } \\
\text { profissionais da equipe e } \\
\text { comunidade. }\end{array}$ \\
\hline $\begin{array}{l}\text { Agente comunitário } \\
\text { de saúde: estratégias } \\
\text { e consequências da } \\
\text { sua rede de relações e } \\
\text { interações }\end{array}$ & $\begin{array}{c}\text { Revista da } \\
\text { Rede de } \\
\text { Enfermagem } \\
\text { do Nordeste } \\
\text { (2014) }\end{array}$ & $\begin{array}{l}\text { Lanzoni, } \\
\text { Cechinel e } \\
\text { Meirelles }\end{array}$ & $\begin{array}{l}\text { Identificar as estratégias } \\
\text { utilizadas pelo ACS em } \\
\text { sua rede de relações } \\
\text { e interações para } \\
\text { melhoria da assistência } \\
\text { à saúde e das suas } \\
\text { repercussões em centro } \\
\text { de saúde. }\end{array}$ & $\begin{array}{l}\text { Estudo } \\
\text { qualitativo }\end{array}$ & Ceará (Brasil) & $\begin{array}{l}\text { Os ACSs são elo entre a } \\
\text { comunidade e o serviço de } \\
\text { saúde, orientam e educam } \\
\text { sobre os serviços oferecidos } \\
\text { pela unidade de saúde; } \\
\text { facilitam o acesso das } \\
\text { pessoas identificadas como } \\
\text { necessitadas de cuidados } \\
\text { específicos. }\end{array}$ \\
\hline $\begin{array}{l}\text { O cuidado em } \\
\text { saúde mental pelos } \\
\text { agentes comunitários } \\
\text { de saúde: o que } \\
\text { aprendem em seu } \\
\text { cotidiano de trabalho? }\end{array}$ & $\begin{array}{c}\text { Physis: Revista } \\
\text { de Saúde } \\
\text { Coletiva } \\
\text { (2014) }\end{array}$ & $\begin{array}{l}\text { Santos e } \\
\text { Nunes }\end{array}$ & $\begin{array}{l}\text { Descrever o } \\
\text { conhecimento } \\
\text { em saúde mental } \\
\text { construído pelo ACS. }\end{array}$ & $\begin{array}{l}\text { Estudo } \\
\text { qualitativo }\end{array}$ & $\begin{array}{c}\text { Rio de Janeiro } \\
\text { (Brasil) }\end{array}$ & $\begin{array}{l}\text { Os ACSs atuam no cuidado } \\
\text { da pessoa com transtorno } \\
\text { mental, orientando suas } \\
\text { famílias; são mediadores de } \\
\text { conflitos, informam acerca } \\
\text { do monitoramento do } \\
\text { usuário quanto ao uso de } \\
\text { psicotrópicos. }\end{array}$ \\
\hline $\begin{array}{l}\text { Ações do agente } \\
\text { comunitário de saúde } \\
\text { no diagnóstico da } \\
\text { tuberculose pulmonar }\end{array}$ & $\begin{array}{c}\text { Revista da } \\
\text { Rede de } \\
\text { Enfermagem } \\
\text { do Nordeste } \\
\text { (2011) }\end{array}$ & $\begin{array}{l}\text { Dantas } \\
\text { et al. }\end{array}$ & $\begin{array}{l}\text { Analisar as ações do } \\
\text { ACS no diagnóstico da } \\
\text { tuberculose pulmonar } \\
\text { na APS. }\end{array}$ & $\begin{array}{l}\text { Estudo } \\
\text { quantitativo }\end{array}$ & $\begin{array}{c}\text { Ceará } \\
\text { (Brasil) }\end{array}$ & $\begin{array}{l}\text { Os ACSs orientam sobre } \\
\text { sintomas respiratórios e } \\
\text { coleta do escarro. A maioria } \\
\text { não encontrou dificuldade } \\
\text { em convencer o usuário a } \\
\text { colher o escarro. }\end{array}$ \\
\hline $\begin{array}{l}\text { O Programa de Agentes } \\
\text { Comunitários de Saúde } \\
\text { no Ceará: o caso de } \\
\text { Uruburetama }\end{array}$ & $\begin{array}{c}\text { Ciência \& } \\
\text { Saúde Coletiva } \\
\text { (2011) }\end{array}$ & Ávila & $\begin{array}{l}\text { Identificar as práticas dos } \\
\text { ACSs em Uruburetama, } \\
\text { Ceará. }\end{array}$ & $\begin{array}{l}\text { Estudo } \\
\text { qualitativo }\end{array}$ & $\begin{array}{c}\text { Rio de Janeiro } \\
\text { (Brasil) }\end{array}$ & $\begin{array}{l}\text { Elo entre comunidade e } \\
\text { equipe de saúde; orienta } \\
\text { sobre adoecimento, } \\
\text { alimentação e nutrição infantil; } \\
\text { acompanhamento de gestantes } \\
\text { e nutrizes; crescimento e } \\
\text { desenvolvimento infantil; não } \\
\text { recebe capacitações condizentes } \\
\text { com suas atividades. }\end{array}$ \\
\hline
\end{tabular}

continua > 
Continuação - Quadro 2

\begin{tabular}{|c|c|c|c|c|c|c|}
\hline \multicolumn{7}{|c|}{ escrição dos estudos publicados entre 2010 e 2014 relacionados às ações realizadas pelo ACS na APS, 2015} \\
\hline Título do artigo & $\begin{array}{l}\text { Periódico } \\
\text { e ano de } \\
\text { publicação }\end{array}$ & Autores & Objetivo do estudo & $\begin{array}{l}\text { Tipo de } \\
\text { estudo }\end{array}$ & $\begin{array}{l}\text { Estado/ } \\
\text { Localidade } \\
\text { e país da } \\
\text { publicação }\end{array}$ & $\begin{array}{c}\text { Atividades realizadas } \\
\text { pelo ACS }\end{array}$ \\
\hline $\begin{array}{l}\text { Grupos focais com } \\
\text { agentes comunitários } \\
\text { de saúde: subsídios } \\
\text { para entendimento } \\
\text { destes atores sociais }\end{array}$ & $\begin{array}{c}\text { Revista } \\
\text { Enfermagem } \\
\text { da Uerj (2010) }\end{array}$ & $\begin{array}{l}\text { Coriolano e } \\
\text { Lima }\end{array}$ & $\begin{array}{l}\text { Descrever o processo de } \\
\text { trabalho do ACS. }\end{array}$ & $\begin{array}{l}\text { Estudo } \\
\text { qualitativo }\end{array}$ & $\begin{array}{l}\text { Rio de Janeiro } \\
\text { (Brasil) }\end{array}$ & $\begin{array}{l}\text { Assistência e cadastro de } \\
\text { indivíduos/famílias; apoio } \\
\text { educativo; organização de } \\
\text { prontuários; elo entre ESF e } \\
\text { necessidades/demandas da } \\
\text { população; encaminhamento } \\
\text { de problemas para outros } \\
\text { membros ou para outros } \\
\text { níveis de complexidade; } \\
\text { ocupa posição ativa ante } \\
\text { questões sociais e ao mesmo } \\
\text { tempo passiva, por não } \\
\text { encontrar soluções efetivas. }\end{array}$ \\
\hline $\begin{array}{l}\text { Is the value of } \\
\text { Community } \\
\text { Healthcare Agents in } \\
\text { Brazil's Family Health } \\
\text { Strategy receiving full } \\
\text { recognition? }\end{array}$ & $\begin{array}{c}\text { Ciência \& } \\
\text { Saúde Coletiva } \\
\text { (2016) }\end{array}$ & $\begin{array}{l}\text { Guanaes- } \\
\text { Lorenzi e } \\
\text { Pinheiro }\end{array}$ & $\begin{array}{l}\text { Discutir sentidos } \\
\text { produzidos por ACSs de } \\
\text { uma cidade pequena } \\
\text { de São Paulo sobre sua } \\
\text { (des)valorização. }\end{array}$ & $\begin{array}{l}\text { Estudo } \\
\text { qualitativo }\end{array}$ & $\begin{array}{c}\text { Rio de Janeiro } \\
\text { (Brasil) }\end{array}$ & $\begin{array}{l}\text { Atividades já descritas, mas } \\
\text { são tensionadas por sentidos } \\
\text { de desvalorização referidos } \\
\text { a aspectos macroestruturais: } \\
\text { baixos salários e pouco } \\
\text { reconhecimento de sua } \\
\text { função comparativamente a } \\
\text { profissionais de nível superior. }\end{array}$ \\
\hline $\begin{array}{l}\text { Agente comunitário } \\
\text { de saúde: elemento } \\
\text { nuclear das ações em } \\
\text { saúde }\end{array}$ & $\begin{array}{c}\text { Ciência \& } \\
\text { Saúde Coletiva } \\
\text { (2013) }\end{array}$ & Costa et al. & $\begin{array}{l}\text { Identificar as ações } \\
\text { desenvolvidas pelo } \\
\text { ACS vinculado à saúde } \\
\text { da família de Montes } \\
\text { Claros, MG, Brasil. }\end{array}$ & $\begin{array}{l}\text { Estudo } \\
\text { quantitativo }\end{array}$ & $\begin{array}{c}\text { Rio de Janeiro } \\
\text { (Brasil) }\end{array}$ & $\begin{array}{l}\text { Realiza cadastro, visita } \\
\text { familiar, identificação e } \\
\text { informação de riscos à equipe, } \\
\text { orientação quanto ao uso dos } \\
\text { serviços de saúde; encaminha } \\
\text { e agenda consultas/exames, } \\
\text { realiza educação em saúde } \\
\text { e participa de reflexão do } \\
\text { trabalho em equipe; uma } \\
\text { parcela auxilia no ambiente } \\
\text { clínico. }\end{array}$ \\
\hline $\begin{array}{l}\text { The provision of TB and } \\
\text { HIV/Aids treatment } \\
\text { support by lay health } \\
\text { workers in South } \\
\text { Africa: a time-and- } \\
\text { motion study }\end{array}$ & $\begin{array}{l}\text { Human } \\
\text { Resources } \\
\text { for Health } \\
\text { (2014) }\end{array}$ & $\begin{array}{l}\text { Odendaal e } \\
\text { Lewin }\end{array}$ & $\begin{array}{l}\text { Compreender como } \\
\text { ACSs organizam e } \\
\text { estruturam seu tempo } \\
\text { na prestação de apoio } \\
\text { e adesão ao tratamento } \\
\text { de pessoas com TB e } \\
\text { tratamento ou terapia } \\
\text { antirretroviral na África } \\
\text { do Sul. }\end{array}$ & $\begin{array}{c}\text { Estudo } \\
\text { quantitativo }\end{array}$ & $\begin{array}{l}\text { Grande } \\
\text { Londres } \\
\text { (Inglaterra) }\end{array}$ & $\begin{array}{l}\text { Realiza cuidados médicos } \\
\text { e apoio social, assim como } \\
\text { avaliação de moradia para } \\
\text { determinar os riscos para } \\
\text { a adesão ao tratamento e } \\
\text { constatação dos pacientes } \\
\text { que abandonam seu } \\
\text { tratamento. }\end{array}$ \\
\hline
\end{tabular}


Continuação - Quadro 2

\begin{tabular}{|c|c|c|c|c|c|c|}
\hline Título do artigo & $\begin{array}{l}\text { Periódico } \\
\text { e ano de } \\
\text { publicação }\end{array}$ & Autores & Objetivo do estudo & $\begin{array}{l}\text { Tipo de } \\
\text { estudo }\end{array}$ & $\begin{array}{l}\text { Estado/ } \\
\text { Localidade } \\
\text { e país da } \\
\text { publicação }\end{array}$ & $\begin{array}{c}\text { Atividades realizadas } \\
\text { pelo ACS }\end{array}$ \\
\hline $\begin{array}{l}\text { Innovative primary care } \\
\text { delivery in rural Alaska: } \\
\text { a review of patient } \\
\text { encounters seen by } \\
\text { community health aides. }\end{array}$ & $\begin{array}{l}\text { International } \\
\text { Journal of } \\
\text { Circumpolar } \\
\text { Health (2012) }\end{array}$ & $\begin{array}{l}\text { Golnick } \\
\text { et al. }\end{array}$ & $\begin{array}{l}\text { Descrever a prática clínica } \\
\text { dos ACSs, profissionais } \\
\text { da APS, em comunidades } \\
\text { rurais do Alasca. }\end{array}$ & $\begin{array}{c}\text { Estudo } \\
\text { quantitativo }\end{array}$ & $\begin{array}{c}\text { Northern } \\
\text { Ostrobothnia } \\
\text { (Finlândia) }\end{array}$ & $\begin{array}{l}\text { Realiza diagnósticos; visitas } \\
\text { domiciliares; ações preventivas e } \\
\text { de emergência; procedimentos; } \\
\text { recebe pacientes para consultas } \\
\text { em clínicas e entregam } \\
\text { medicamentos. }\end{array}$ \\
\hline $\begin{array}{l}\text { Agente comunitário de } \\
\text { saúde: sujeito da prática } \\
\text { em saúde bucal em } \\
\text { Alagoinhas, Bahia }\end{array}$ & $\begin{array}{c}\text { Ciência \& } \\
\text { Saúde Coletiva } \\
\text { (2010) }\end{array}$ & $\begin{array}{c}\text { Rodrigues, } \\
\text { Santose } \\
\text { Assis }\end{array}$ & $\begin{array}{l}\text { Analisar o papel do } \\
\text { ACS no cotidiano } \\
\text { da equipe de saúde } \\
\text { bucal em Alagoinhas } \\
\text { (BA), considerando a } \\
\text { construção de saberes e } \\
\text { práticas. }\end{array}$ & $\begin{array}{c}\text { Estudo } \\
\text { qualitativo }\end{array}$ & $\begin{array}{c}\text { Rio de Janeiro } \\
\text { (Brasil) }\end{array}$ & $\begin{array}{l}\text { Realiza visita domiciliar; } \\
\text { acompanha desenvolvimento } \\
\text { e peso de crianças, gestantes, } \\
\text { idosos, hipertensos e diabéticos; } \\
\text { atende grupos da comunidade e } \\
\text { vulneráveis; promove educação } \\
\text { em saúde bucal; é articulador } \\
\text { entre equipe e comunidade. }\end{array}$ \\
\hline $\begin{array}{l}\text { Task-shifting and } \\
\text { prioritization: a } \\
\text { situational analysis } \\
\text { examining the role } \\
\text { and experiences } \\
\text { of community health } \\
\text { workers in Malawi. }\end{array}$ & $\begin{array}{l}\text { Human } \\
\text { Resources for } \\
\text { Health } \\
\text { (2014) }\end{array}$ & Smith et al. & $\begin{array}{l}\text { Compreender as } \\
\text { atividades realizadas } \\
\text { pelos ACSs, quando } \\
\text { comparadas com } \\
\text { documentos, para } \\
\text { examinar as tarefas } \\
\text { priorizadas. }\end{array}$ & $\begin{array}{c}\text { Estudo } \\
\text { qualitativo }\end{array}$ & $\begin{array}{c}\text { Grande } \\
\text { Londres } \\
\text { (Inglaterra) }\end{array}$ & $\begin{array}{l}\text { Realiza tarefas fora de sua } \\
\text { competência - testes de TB, } \\
\text { distribuição de medicamentos } \\
\text { e contraceptivos; administra } \\
\text { injeções; controle da terapia } \\
\text { antirretroviral; gestão de cólera; } \\
\text { administração de farmácias e } \\
\text { registro ambulatorial. }\end{array}$ \\
\hline $\begin{array}{l}\text { Community care workers, } \\
\text { poor referral networks } \\
\text { and consumption of } \\
\text { personal resources in } \\
\text { rural South Africa. }\end{array}$ & $\begin{array}{c}\text { Plos One } \\
\text { (2014) }\end{array}$ & Sips et al. & $\begin{array}{l}\text { Explorar os padrões } \\
\text { e práticas de } \\
\text { encaminhamento } \\
\text { de usuários pelos } \\
\text { trabalhadores de } \\
\text { cuidados comunitários. }\end{array}$ & $\begin{array}{c}\text { Estudo } \\
\text { qualitativo }\end{array}$ & $\begin{array}{l}\text { Califórnia } \\
\text { (Estados } \\
\text { Unidos da } \\
\text { América) }\end{array}$ & $\begin{array}{l}\text { Facilita o acesso por meio de } \\
\text { orientações, como sintomas } \\
\text { de TB e HIV; realiza visitas } \\
\text { domiciliares. }\end{array}$ \\
\hline $\begin{array}{l}\text { It's the sense of } \\
\text { responsibility that } \\
\text { keeps you going': } \\
\text { stories and experiences } \\
\text { of participation from } \\
\text { rural community health } \\
\text { workers in Guatemala }\end{array}$ & $\begin{array}{l}\text { Archives of } \\
\text { Public Health } \\
\text { (2012) }\end{array}$ & Ruano et al. & $\begin{array}{l}\text { Explorar como os valores } \\
\text { e motivação pessoais } \\
\text { dos trabalhadores de } \\
\text { saúde da comunidade } \\
\text { influenciam a experiência } \\
\text { nos cuidados de saúde } \\
\text { primários. }\end{array}$ & $\begin{array}{c}\text { Estudo } \\
\text { qualitativo }\end{array}$ & $\begin{array}{c}\text { Grande } \\
\text { Londres } \\
\text { (Inglaterra) }\end{array}$ & $\begin{array}{l}\text { Elo entre comunidade e } \\
\text { equipes de saúde; ações de } \\
\text { cuidado e promoção da saúde } \\
\text { em comunidades rurais e } \\
\text { isoladas. }\end{array}$ \\
\hline $\begin{array}{l}\text { Cultural competence and } \\
\text { perceptions of community } \\
\text { health workers' } \\
\text { effectiveness for reducing } \\
\text { health care disparities }\end{array}$ & $\begin{array}{l}\text { Journal of } \\
\text { Primary Care } \\
\text { \& Community } \\
\text { Health (2015) }\end{array}$ & $\begin{array}{l}\text { Mobula } \\
\text { et al. }\end{array}$ & $\begin{array}{l}\text { Investigar a competência } \\
\text { cultural do ACS. }\end{array}$ & $\begin{array}{c}\text { Estudo } \\
\text { quantitativo }\end{array}$ & $\begin{array}{l}\text { Califórnia } \\
\text { (Estados } \\
\text { Unidos da } \\
\text { América) }\end{array}$ & $\begin{array}{l}\text { Atividades com competência } \\
\text { cultural, que permitem } \\
\text { integração efetiva nos serviços } \\
\text { e buscam reduzir disparidades } \\
\text { em saúde. }\end{array}$ \\
\hline
\end{tabular}

continua > 
Continuação - Quadro 2

\begin{tabular}{|c|c|c|c|c|c|c|}
\hline \multicolumn{7}{|c|}{ Descrição dos estudos publicados entre 2010 e 2014 relacionados às ações realizadas pelo ACS na APS, 2015} \\
\hline Título do artigo & $\begin{array}{l}\text { Periódico } \\
\text { e ano de } \\
\text { publicação }\end{array}$ & Autores & Objetivo do estudo & $\begin{array}{l}\text { Tipo de } \\
\text { estudo }\end{array}$ & $\begin{array}{l}\text { Estado/ } \\
\text { Localidade } \\
\text { e país da } \\
\text { publicação }\end{array}$ & $\begin{array}{c}\text { Atividades realizadas } \\
\text { pelo ACS }\end{array}$ \\
\hline $\begin{array}{l}\text { Community health } \\
\text { workers and mobile } \\
\text { technology: a systematic } \\
\text { review of the literature }\end{array}$ & $\begin{array}{l}\text { Plos One } \\
\text { (2013) }\end{array}$ & Braun et al. & $\begin{array}{c}\text { Avaliar o uso de } \\
\text { tecnologias pelo ACS. }\end{array}$ & $\begin{array}{c}\text { Estudo } \\
\text { quantitativo }\end{array}$ & $\begin{array}{c}\text { Califórnia } \\
\text { (Estados Unidos } \\
\text { da América) }\end{array}$ & $\begin{array}{l}\text { Atividades em locais de poucos } \\
\text { recursos; fornece primeira } \\
\text { linha de cuidados; cada vez } \\
\text { mais, as tecnologias móveis } \\
\text { são desenvolvidas, testadas e } \\
\text { implementadas para facilitar as } \\
\text { tarefas e melhorar os resultados. }\end{array}$ \\
\hline $\begin{array}{l}\text { A systematic community- } \\
\text { based participatory } \\
\text { approach to refining } \\
\text { an evidence based } \\
\text { community-level } \\
\text { intervention: the HOLA } \\
\text { intervention for Latino men } \\
\text { who have sex with men }\end{array}$ & $\begin{array}{c}\text { Health } \\
\text { Promotion } \\
\text { Practice (2013) }\end{array}$ & $\begin{array}{l}\text { Rhodes } \\
\text { et al. }\end{array}$ & $\begin{array}{l}\text { Descrever intervenções } \\
\text { para promover a saúde } \\
\text { sexual para homens } \\
\text { latinos que fazem sexo } \\
\text { com homens. }\end{array}$ & $\begin{array}{c}\text { Estudo } \\
\text { quantitativo }\end{array}$ & $\begin{array}{l}\text { Illinois (Estados } \\
\text { Unidos da } \\
\text { América) }\end{array}$ & $\begin{array}{l}\text { O ACS participou de } \\
\text { intervenção para treinar } \\
\text { homens gays latinos para } \\
\text { atuarem como conselheiros } \\
\text { de saúde. }\end{array}$ \\
\hline $\begin{array}{l}\text { Community health } \\
\text { worker home visits } \\
\text { for Medicaid-enrolled } \\
\text { children with asthma: } \\
\text { effects on asthma } \\
\text { outcomes and costs }\end{array}$ & $\begin{array}{l}\text { American } \\
\text { Journal of } \\
\text { Public Health } \\
\quad \text { (2015) }\end{array}$ & $\begin{array}{l}\text { Campbell } \\
\text { et al. }\end{array}$ & $\begin{array}{l}\text { Avaliar se a visita do } \\
\text { ACS apresenta eficácia } \\
\text { terapêutica no } \\
\text { controle da asma em } \\
\text { crianças. }\end{array}$ & $\begin{array}{c}\text { Estudo } \\
\text { quantitativo }\end{array}$ & $\begin{array}{l}\text { Nova York } \\
\text { (Estados } \\
\text { Unidos da } \\
\text { América) }\end{array}$ & $\begin{array}{l}\text { Realiza visita domiciliar, com } \\
\text { eficácia terapêutica no controle } \\
\text { da asma em crianças e melhora } \\
\text { nos resultados de saúde. }\end{array}$ \\
\hline $\begin{array}{l}\text { Community health } \\
\text { workers: an integral part } \\
\text { of an integrated health } \\
\text { care team }\end{array}$ & $\begin{array}{l}\text { North Carolina } \\
\text { Medical } \\
\text { Journal (2016) }\end{array}$ & $\begin{array}{l}\text { Nelson, } \\
\text { Money Jr. e } \\
\text { Petersen }\end{array}$ & $\begin{array}{c}\text { Descrever o papel do ACS } \\
\text { como parte importante que } \\
\text { integra equipe de cuidados } \\
\text { integrados de saúde. }\end{array}$ & $\begin{array}{c}\text { Estudo } \\
\text { quantitativo }\end{array}$ & $\begin{array}{l}\text { Carolina do } \\
\text { Norte (Estados } \\
\text { Unidos da } \\
\text { América) }\end{array}$ & $\begin{array}{l}\text { Executa atividades de } \\
\text { prevenção de agravos e } \\
\text { promoção da saúde; contribui } \\
\text { para a integralidade do } \\
\text { cuidado. }\end{array}$ \\
\hline $\begin{array}{l}\text { Mounting evidence of } \\
\text { the effectiveness and } \\
\text { versatility of community } \\
\text { health workers. }\end{array}$ & $\begin{array}{c}\text { American } \\
\text { Journal of } \\
\text { Public Health } \\
\text { (2016) }\end{array}$ & $\begin{array}{l}\text { Landers e } \\
\text { Levinson }\end{array}$ & $\begin{array}{l}\text { Descrever evidências } \\
\text { sobre a efetividade e a } \\
\text { versatilidade do ACS. }\end{array}$ & $\begin{array}{c}\text { Estudo } \\
\text { quantitativo }\end{array}$ & $\begin{array}{l}\text { Nova York } \\
\text { (Estados } \\
\text { Unidos da } \\
\text { América) }\end{array}$ & $\begin{array}{l}\text { Exerce atividades que lhe } \\
\text { conferem versatilidade, presta } \\
\text { atenção à comunidade LGBT e } \\
\text { às pessoas vivendo com o HIV. }\end{array}$ \\
\hline
\end{tabular}

Fonte: As autoras.

\section{Revisão integrativa: resultados}

Os 27 artigos se encontram, sobretudo, nas bases (Quadro 1): Lilacs - nove artigos (35,85\%); SciELO - seis $(29,58 \%)$, com estudos publicados, em sua maioria, em 2014 - oito (40\%); e 2012 - cinco (24\%) (Quadro 2). São $16(59,2 \%)$ produções brasileiras e 11 (40,8\%) estrangeiras. Dos artigos brasileiros, $14(87,5 \%)$ são oriundos de instituições de ensino superior públicas, 
estaduais ou federais; e dois $(12,5 \%)$ de instituições privadas. O Sudeste tem mais publicações, 12 (71\%), seguido pelo Nordeste, com três (21\%). Os artigos internacionais são de instituições privadas da Europa - quatro $(36,3 \%)-\mathrm{e}$ públicas dos EUA - sete $(63,7 \%)$.

A Revista da Rede de Enfermagem do Nordeste (Rene) publicou dois artigos (10,54\%), acompanhada dos periódicos Ciência \& Saúde Coletiva (quatro - 12,54\%), American Journal of Public Health, Human Resources for Health e Plos One, cada um com dois $(12,5 \%)$. Sedes dos periódicos brasileiros: São Paulo - cinco $(35,72 \%)$; e Rio de Janeiro - sete $(37,72 \%)$. Sobre as revistas internacionais: Grande Londres - três $(15,78 \%)$; e Califórnia - três $(15,78 \%)$.

Metodologicamente, 11 (40,7\%) artigos têm caráter qualitativo e 16 (59,3\%), quantitativo.

Os estudos nacionais objetivaram identificar, analisar, caracterizar e avaliar as práticas exercidas pelo ACS; ações de cuidado específicas; situações de violência doméstica; e apresentar estratégias para a melhoria do cuidado. Os internacionais descreveram como a motivação pessoal influencia as práticas de cuidado, as ações realizadas, a organização do tempo no cuidado oferecido e os encaminhamentos.

Concluem os estudos nacionais que o ACS é elo entre comunidade e ESF no monitoramento de casos e resultados de intervenções; facilita o acesso à unidade; cadastra famílias e identifica situações de risco; visita domicílios; encaminha para consultas; promove vigilância e ações de educação em saúde; reflete sobre trabalho e mobilidade comunitária; realiza atividades com grupos prioritários e ações para agilizar o trabalho. Também descrevem a inserção do ACS no mercado de trabalho. Tais publicações mostram o papel preponderante do ACS como elo entre comunidade e equipe de saúde, repassando-lhe suas condições de saúde, demandas e ofertas de cuidado com base nas necessidades dos usuários, além de facilitar o acesso daqueles que precisam de atendimento (Costa e Araújo, 2013; Sakata e Mishima, 2012; Filgueiras e Silva, 2011; Silva et al., 2012; Lanzoni, Cechinel e Meirelles, 2014; Santos e Nunes, 2014; Ávila, 2011, Rodrigues, Santos e Assis, 2010).

Os artigos internacionais destacam que o ACS realiza visita domiciliar; entrega medicamentos; orienta, monitora e avalia o tratamento de tuberculose (TB) e HIV, medicação correta e controle de efeitos colaterais, além de práticas para garantir adesão, diagnóstico e procedimentos de enfermagem e médicos; e descrevem a inserção do agente comunitário de saúde no mercado de trabalho. O ACS também exerce a função de elo, como verificado na Guatemala e no nordeste da África (Ruano et al., 2012; Odendaal e Lewin, 2014). Sua vinculação à equipe coloca-o como mediador entre a comunidade e o serviço de saúde, agente social para a organização e a transformação das condições comunitárias. Conhecendo a comunidade, o ACS potencializa sua proximidade com a ESF. Expõe-se aos contextos de pobreza e violência, o que exige estra- 
tégias de preservação de integridade física e emocional (Gomes et al., 2010; Jardim e Lancman, 2009; Cardoso e Nascimento, 2010).

Para a apresentação e a organização dos artigos, estabeleceram-se três categorias: 'Agente comunitário de saúde: função, diversidade de atividades realizadas e papel desempenhado na comunidade'; ‘Fragilidades no fazer do agente comunitário de saúde'; 'Agente comunitário de saúde: inserção no mercado de trabalho'.

\section{Agente comunitário de saúde: função, diversidade de atividades realizadas e papel desempenhado na comunidade}

A vivência do ACS com/na comunidade (Holanda Lavor et al., 2004) e sua participação no cotidiano das coletividades possibilitam atuação via visita domiciliar, atividade mais verificada na revisão. Durante ela, ocorrem outras atividades, educativas e preventivas, orientações e identificação de novas demandas (Cazola et al., 2014; Costa e Araújo, 2013; Filgueiras e Silva, 2011; Crispim et al., 2012; Silva et al., 2012; Moreira et al., 2014; Lanzoni, Cechinel e Meirelles, 2014; Dantas et al., 2011; Rodrigues, Santos e Assis, 2010). No nordeste da África, por exemplo, as visitas objetivam motivar os usuários a realizar e manter tratamentos para TB e HIV (Odendaal e Lewin, 2014). A visita domiciliar propicia a comunicação solidária entre ACS e famílias, fortalece laços de vizinhança e ganho de confiança das equipes de saúde. Eles firmam-se como trabalhadores do sistema de saúde, sem deixar a fidelidade com a comunidade (Holanda Lavor et al., 2004). Tais atividades também são verificadas nos EUA (Witmer et al., 1995; Mobula et al., 2015) e no Reino Unido (Haines et al., 2007; Harris e Haines, 2012).

O ACS é personagem fundamental pela proximidade dos problemas da comunidade e pela facilidade em se comunicar e exercer liderança (Brasil, 2009a; 2009b; Kebian e Acioli, 2011). Esses aspectos destacam sua atuação como facilitador, dada a possibilidade de adentrar na intimidade das famílias, percebendo suas necessidades e as da comunidade. Firma-se o seu papel como apoio social e mediador de conflitos na comunidade (Filgueiras e Silva, 2011; Pinheiro e Guanaes-Lorenzi, 2014; Silva et al., 2012; Moreira et al., 2014; Santos e Nunes, 2014; Coriolano e Lima, 2010), identificando situações de risco das famílias (Costa e Araújo, 2013). Destaca-se a atuação com redes de relacionamentos significativos, como família, amizade, trabalho, estudo e comunidade, além de agências sociais e institucionais. Tal proximidade contribui para a articulação e o fortalecimento de relações entre pessoas de um território e sistemas de cuidado (Silva e Dalmaso, 2002; Guanaes-Lorenzi e Pinheiro, 2016).

Na Guatemala, ações de cuidado e promoção em saúde também acontecem, com destaque para a posição de liderança comunitária, pois os ACSs garan- 
tem o desenvolvimento das comunidades (Ruano et al., 2012). Constatam-se características especiais do ACS: promover saúde junto às famílias, devido à sua capacidade comunicativa (Brasil, 2010), e resolver situações-problema que afetam a qualidade de vida das pessoas (Brasil, 2009b).

Essas atividades são possibilitadas pela inserção do ACS na equipe e na comunidade, por levar às famílias informações adquiridas com a equipe, dialogando e aproximando-as dos serviços de saúde. Ele tem alto potencial de mobilização e articulação de conhecimentos, habilidades, atitudes e valores e realiza educação em saúde (Brasil, 2004a; 2004b; 2010). Nessa diversidade, o ACS contribui para a qualidade de vida das pessoas e da comunidade (Brasil, 2009a; 2009b) e torna-se responsável pela saúde e por ações ético-políticas e econômicas (Leite e Paulon, 2013).

A presença do ACS na comunidade lhe permite desenvolver um saber empírico sobre ela, desconhecido, muitas vezes, pelos demais profissionais. Complementa o saber científico da equipe (Bornstein e Stotz, 2008; Kebian e Acioli, 2014), com respaldo no estabelecimento de novas formas de atuação social e em saúde, via formação solidária de subjetividade e ética em saúde, a partir da história de vida e de seu cotidiano (Ferreira et al., 2009).

Constatou-se a variedade de tarefas realizadas pelo ACS. Para a World Health Organization (2007), uma distinção entre os ACSs pode ser feita de acordo com o tipo de tarefas realizadas. O ACS generalista, presente antes da Declaração de Alma-Ata, ainda atua em países como Brasil e Índia e realiza variadas funções e atividades: visita domiciliar, saneamento ambiental, fornecimento de água, primeiros socorros, educação em saúde, orientações nutricionais, tratamento de doenças comuns, cuidados materno-infantis etc. Contudo, a partir de 1990, cobram-se ações específicas, como saúde materno-infantil, cuidados de TB e HIV/Aids, controle de malária e tratamento das infecções respiratórias agudas; por isso, ele passou a ser reconhecido como especialista. Essa distinção acontece em países como Haiti e República Democrática do Congo.

No Brasil, reconhece-se como generalista pela diversidade de ações desempenhadas, como valorização de ações com mulheres e crianças, de acordo com a política social e de saúde, acompanhamento de grupos de risco - crianças, nutrizes - e controle da dengue (Cazola et al., 2014; Lanzoni, Cechinel e Meirelles, 2014; Ávila, 2011; Rodrigues, Santos e Assis, 2010). Ao ACS solicita-se o acompanhamento prioritário de crianças, objetivando reduzir a morbimortalidade infantil e agravos futuros (Brasil, 2009a). Destaca-se a pertinência da realização de ações diagnósticas no Brasil, como na TB, com investigação da tosse, orientação e coleta de escarro (Dantas et al., 2011). As ações do ACS contribuem para o desenvolvimento integral das crianças na comunidade (Afulani et al., 2012; Campbell et al., 2015). Pesquisa realizada em King County, Seattle, EUA, avaliou que a visita do ACS apresenta eficácia terapêutica no controle da asma em crianças (Campbell et al., 2015). 
Também realizam diagnóstico no Alasca (Ávila, 2011) e cuidados médicos em diferentes regiões da África. Na África do Sul, sua função é garantir a administração correta da medicação para HIV e TB e que os pacientes não experimentem efeitos colaterais; e no nordeste africano, informar e orientar sobre sintomas da TB e HIV (Sips et al., 2014). No sul da África central, é responsável por realizar exames, dispensar medicamentos, inclusive para HIV, e acompanhar esses casos (Smith et al., 2014). Pesquisas internacionais mostram a eficácia do ACS em gestão de doenças crônicas, cuidados de populações vulneráveis, prevenção do câncer e redução do risco cardiovascular (Mobula et al., 2015; Nelson, Money Jr. e Petersen, 2016; Landers e Levinson, 2016). Estudo em Maryland, EUA, revela que comportamentos culturalmente competentes do ACS contribuem para a redução das disparidades em saúde (Mobula et al., 2015).

Contudo, Bornstein e Stotz (2008) alertam para o fato de que a maioria das atribuições mencionadas é composta por atividades relativas aos programas desenvolvidos pelas unidades de saúde, tem caráter biomédico e individual. Ainda que se mencione a necessidade de se promoverem ações coletivas, os instrumentos de informação que devem ser preenchidos pelos ACSs e que fazem parte do Sistema de Informação da Atenção Básica não detalham esse tipo de trabalho. Tal sistema enfatiza as fichas, que permitem a verificação da produtividade baseada em ações individuais e avaliação de indicadores de saúde.

O ACS, nos casos de violência doméstica, é auxiliar da equipe na definição de intervenções e de ações conjuntas com outros profissionais, como assistente social (Moreira et al., 2014). Isso é possível pelo vínculo do ACS com a comunidade, que sustenta sua atuação e práticas de cuidado geradoras de autonomia, por meio do reconhecimento dos usuários como singulares (Leite e Paulon, 2013).

Ações em saúde mental são relevantes: orientação das famílias; mediação de conflitos; conversas; informações sobre profissionais que os familiares cuidadores devem consultar ou acompanhar; e monitoramento quanto ao uso de psicotrópicos (Santos e Nunes, 2014).

Nos EUA, a versatilidade de atividades do ACS inclui a atenção à comunidade de Lésbicas, Gays, Bissexuais, Transgêneros (LGBT) e portadores do HIV, pois o agente constrói relações de confiança com os usuários. Pessoas transgêneras foram recrutadas para realizar os primeiros grupos com foco nas necessidades de saúde dos transgêneros, sendo treinadas para atuar como facilitadores de grupos e na identificação de barreiras no acesso aos serviços de saúde. A comunidade LGBT apoiou a atividade, e seus membros ajudaram a desenvolver e implementar o cuidado (Landers e Levinson, 2016). Na Carolina do Norte, EUA, investiu-se na promoção de saúde sexual para homens latinos que fazem sexo com homens. Nisso, incluíram-se quatro módulos de treinamento para esses usuários atuarem como conselheiros de saúde, e em sua 
realização foram abordados aspectos comportamentais, experiências vividas e valores culturais dos imigrantes (Rhodes et al., 2013).

Diante da complexidade de atribuições, torna-se imprescindível ofertar formação condizente. A educação permanente em saúde, como processo educativo em relação com o trabalho, oportuniza o aprendizado e não transmite informações, por isso pode operar mudanças no cuidado (Ceccim, Bravin e Santos, 2011). A atuação dos ACSs na APS exige qualificação adequada e permanente, para assumir suas atribuições junto à ESF e à comunidade. Investimentos são necessários no treinamento e manutenção da qualidade do trabalho, com supervisão e reflexão em equipe - assim, enfrentando os desafios com segurança e responsabilidade com o SUS e com a APS (Costa et al., 2013). Os trabalhadores devem ser vistos como sujeitos de conhecimento e de cultura, entendendo que o primeiro se dá no exercício profissional. Também há o desafio epistemológico, especialmente quanto aos conhecimentos científicos e aos saberes profissionais técnicos e sociopolíticos, expressos pela relação teoria-prática (Ramos, 2006).

\section{Fragilidades no fazer do agente comunitário de saúde}

Os estudos nacionais (Piccinini e Neves, 2013; Nunes et al., 2002; Tomaz, 2002; Silva e Dalmaso, 2002; Bornstein e Stotz, 2008; Pinto, Silva e Soriano, 2012; Costa et al., 2013; Costa e Araújo, 2013; Maciazeki-Gomes et al., 2016) e internacionais (Haines et al., 2007; Roman, Raffo e Meghea, 2012; Mobula et al., 2015; Landers e Levinson, 2016; Nelson, Money Jr. e Petersen, 2016) ressaltam o ACS como elemento nuclear das ações em saúde da família: assumindo o papel de mediação e articulação entre equipe de saúde e comunidade - o que propõe a identidade do ACS como híbrida e polifônica (Nunes et al., 2002). Mas deve-se ponderar sobre a forma como é feita a mediação, que pode assumir um caráter vertical na medida em que o serviço prioriza suas orientações na comunidade e procura convencer a população com relação ao saber técnico-científico. A dimensão transformadora da mediação se concretizaria à medida que existissem maior compartilhamento do conhecimento e maior permeabilidade dos serviços com relação às necessidades e demandas da população (Bornstein e Stotz, 2008).

Em estudos no Reino Unido, considerou-se que o ACS não é panaceia para sistemas de saúde frágeis; necessita de tarefas mais focadas, treinamento, supervisão e participação ativa nas comunidades em que trabalha (Haines et al., 2007; Harris e Haines, 2012). Similarmente, nos EUA, o ACS está em posição crítica: questiona-se como melhorar os indicadores de saúde com poucos recursos financeiros, sem apoio substancial num sistema de saúde ineficiente, com redundâncias e incentivos desalinhados (Landers e Levinson, 2016). 
No Brasil, a identidade do ACS tem suas raízes históricas. Desde a proposição do auxiliar de saúde, em 1976, com graus variados da ênfase, identificam-se duas dimensões principais da sua proposta de atuação: uma estritamente técnica, relacionada ao atendimento aos indivíduos e às famílias, à intervenção para prevenção de agravos ou para o monitoramento de grupos ou problemas específicos; outra mais política, não apenas de solidariedade e inserção da saúde no contexto geral de vida, mas no sentido de organização e participação da comunidade. Esse componente político expressa, na dependência da proposta considerada, duas expectativas diversas ou complementares: o agente como um elemento de reorientação da concepção e do modelo de atenção à saúde, de discussão com a comunidade, de apoio ao autocuidado (componente mais ético-comunitário); e o agente como fomentador da organização da comunidade para cidadania e inclusão, numa concepção de transformação social. Outro aspecto encontrado na prática, mas não relacionado às suas atribuições, é a dimensão de assistência social. Ao ACS cabe o desafio de unir o polo técnico ao político das propostas (Silva e Dalmaso, 2002; Tomaz, 2002; Bornstein e Stotz, 2008).

Pesquisas apresentaram dificuldades do ACS em discernir quais são suas atribuições, mostrando ações que fogem à sua competência, a exemplo de agendamento de consultas e exames, entrega de encaminhamentos, medicamentos e recados da equipe para a comunidade (Sakata e Mishima, 2012; Crispim et al., 2012; Silva et al., 2012) e também trabalho administrativo (Crispim et al., 2012; Coriolano e Lima, 2010) e burocrático. A não clareza das demandas da população, assim como a oferta de capacitações descontextualizadas e a falta de apoio das equipes da ESF, leva o ACS a permitir a cobrança de ações incongruentes (Ávila, 2011).

Em Montes Claros, Minas Gerais, encontraram-se atividades que não integram as atribuições do ACS. O auxílio no ambiente clínico cabe aos profissionais técnicos e auxiliares, especialistas autorizados pelos órgãos de regulamentação de suas atividades, não sendo, tais funções, atribuição do ACS, apesar de essa situação ser identificada. No ambiente clínico, normalmente, ele assume funções administrativas, como agendamento de consultas e exames, conferência de estoque de material de escritório e médico-hospitalar, o que se deve à falta de recursos humanos para atender a essa demanda. Outros procedimentos detectados foram a realização de desinfecção e esterilização de instrumental clínico e serviços administrativos não relacionados à sua atuação. Essas condutas desviam o ACS de sua função comunitária e de vigilante, podendo sobrecarregá-lo e diminuir o tempo disponível para a execução de suas tarefas (Costa et al., 2013).

Outras atividades sobrecarregam o ACS, como o trabalho em áreas descobertas e fora do horário (Silva et al., 2012) e a escassez de profissionais de saúde em determinadas regiões, aumentando sua lista de tarefas, sem haver 
treinamento adequado - o que promove sobrecarga e exercício de função especializada (Smith et al., 2014). Ações que extrapolam as competências do ACS denotam que ele não possui atribuições ou saber, o que deslegitima ou questiona sua possibilidade de inovação. Outros profissionais veem o ACS como trabalhador manual (Ferreira et al., 2009). Algumas publicações apresentam suas ações como frágeis, pois se concentram na doença, e a equipe de ESF, muitas vezes, desvaloriza o que ele realiza (Pinheiro e Guanaes-Lorenzi, 2014).

Observam-se hibridez e polifonia no trabalho pelas demandas da comunidade, que lhe inscrevem uma demanda pessoal, e pela equipe de saúde, que exige práticas técnicas e pedagógicas (Piccinini e Neves, 2013; Bornstein e Stotz, 2008), em razão do enfrentamento de situações culturais, religiosas, educativas e econômicas (Brasil, 2010). No nordeste da África, o ACS concede dinheiro e alimentos próprios para pacientes que acompanha. Apesar de reconhecer que isso não é sua atribuição, ele o faz para promover tratamento contra o HIV, pela necessária ingestão de alimentos antes do medicamento, colocando-se em situação de vulnerabilidade (Sips et al., 2014). Na África do Sul, o ACS gasta mais tempo na locomoção do que no contato com o paciente (Golnick et al., 2012), devido às condições.

Revisão sistemática de literatura mostrou que o ACS recebe pouco acompanhamento e auxílio da rede de atendimento do município e da equipe. O pouco uso de tecnologia móvel para registro, comunicação com a equipe e informatização dos dados, que conferiria otimização do processo de acompanhamento, também compõe o quadro de dificuldades no processo de trabalho. Cada vez mais, as tecnologias móveis devem ser desenvolvidas, testadas e implementadas para facilitar as tarefas e melhorar os resultados (Braun et al., 2013). As dificuldades são apontadas como possibilidades de inovação, novas possibilidades acerca do 'como fazer' (Leite e Paulon, 2013).

Também há questões que ultrapassam o alcance das ações de saúde. Condições de vida da população, como pobreza, falta de alimentos, moradia insalubre, água contaminada, lixo, são oriundas de determinantes socioeconômicos que fazem o ACS se sentir impotente; devem ser consideradas no planejamento das ações de saúde. O agente comunitário conhece o meio onde desenvolve suas ações e, na maioria das vezes, nele vive, não significando que tenha uma compreensão maior sobre a realidade, pois lhe falta auxílio no processo de autoconhecimento. Sua capacitação deveria contribuir para uma compreensão mais crítica e profunda da realidade, de sua razão de ser, e de como contribuir, a partir da posição que ocupa na APS (Bornstein e Stotz, 2008; Ávila, 2011).

Entre as fragilidades no cotidiano do ACS, está a hierarquia presente nas categorias profissionais. Contribui para a sua desvalorização o modo como a equipe constrói sua prática, comumente sustentando distinções entre ações mais ou menos importantes, em detrimento de uma visão global da assistência em saúde. Deve haver uma organização das unidades de saúde da família que valorize os diferentes 
saberes e práticas presentes nas funções desempenhadas. Tal organização pode ser importante para que o ACS se perceba como essencial ao bom funcionamento da APS, não mero transmissor de informações aos profissionais de nível superior, pelas qualidades inerentes à sua atuação, saber local, capacidade de diálogo e acolhimento (Silva e Dalmaso, 2002; Tomaz, 2002; Guanaes-Lorenzi e Pinheiro, 2016). O trabalho em equipe na saúde da família deve ser reavaliado por seus membros: da inclusão do ACS no planejamento das atividades à execução e avaliação, assim como reuniões, tudo pode ser espaço adequado para mobilização, de modo a permitir a aproximação dos profissionais, com trocas e crescimento, e facilitar as relações com a comunidade (Costa et al., 2013).

\section{Agente comunitário de saúde: inserção no mercado de trabalho}

A inserção do ACS no mercado de trabalho se dá de variadas formas. Em 1980, na Jamaica, no primeiro encontro internacional para a definição do papel do ACS, constatou-se a variedade de remuneração e escolaridade: trabalhadores assalariados, com ou sem direitos trabalhistas, que recebiam pequenos valores, e os voluntários. Quanto à escolaridade, variava de nenhuma até nível médio, e a sua qualificação situava-se entre seis meses e dois anos (World Health Organization, 1989; Walt, 1990).

No Brasil, a lei n. 10.507, de 10/07/2002, criou a profissão de ACS, conforme a Classificação Brasileira de Ocupações (CBO), elaborada pelo Ministério do Trabalho e Emprego; possui código 5151-05 como trabalhador em promoção e apoio à saúde, especificamente visitador de saúde (Brasil, 2015a). Reivindicações têm sido feitas pela categoria profissional para melhorias na formação profissional, vínculo e remuneração (Carneiro e Martins, 2015), que paulatinamente têm sido alcançadas.

A formação profissional do ACS se apoia no modelo de produção social de saúde, com referência às demandas de saúde da população. Seu foco é modificar as práticas profissionais e a organização do trabalho, articular saber científico e popular via educação crítico-reflexiva e metodologia problematizadora (Gomes et al., 2010). O parecer do Conselho Nacional de Educação CNE/CEB n. 19/2004 (Brasil, 2004a) definiu a necessidade de formação técnica do ACS ofertada pelas escolas técnicas de saúde e centros formadores de recursos humanos em saúde que compõem a Rede de Escolas Técnicas do SUS, em contradição ao que se exigia antes: aprovação em curso introdutório de formação inicial e continuada para ACS. Essa nova proposta substitui a formação rápida e abreviada, em serviço, sem exigência de escolaridade ou carga horária definida, pois bastavam-lhe leitura e escrita (Morosini, 2010).

Na Guatemala, não há uma formação específica para o ACS, o que garantiria melhor oferta de trabalho (Ruano, 2012). Também no sul da África Central não ocorre treinamento adequado (Smith et al., 2014). Os sistemas de 
saúde que se sustentam na atuação do ACS deflagram contradições ao reduzir sua qualificação e ter expectativas em suas atividades (Fonseca, Morosini e Mendonça, 2013). Apesar de a escolarização não ser garantia de melhores condições de vida, ela oferece ao ACS, profissional proveniente das camadas populares, reconhecimento social e profissional (Mota e David, 2010).

Quanto à remuneração, no nordeste da África (Odendaal e Lewin, 2014) e na Guatemala (Ruano et al., 2012) eles não são remunerados e atuam voluntariamente; na Cidade do Cabo e no sul da África Central, atuam sem remuneração adequada, pois os valores recebidos não condizem com o trabalho exercido; ocorre uma desvalorização entre o que se realiza e o que se recebe (Sips et al., 2014; Smith et al., 2014). No Brasil, a inserção do ACS nas equipes de ESF acontece por meio de contratações terceirizadas, precarizando seus vínculos empregatícios com baixos salários. A contratação por processo seletivo, instituída pela lei n. 11.350, de 5/10/2006, tentou legalizar vínculo e admissão, porque a exigência de residir na comunidade contraria o acesso igualitário e universalista via concurso público (Brasil, 2006b; Morosini, 2010).

Essa lei sofreu alterações com a lei n. 12.994, de 17 de junho de 2014 (Brasil, 2014)], que fixou piso salarial nacional e regulamentou plano de carreira, pelo decreto n. 8.474/2015 (Brasil, 2015b). A qualificação e a profissionalização do ACS geram satisfação pessoal e profissional (Lunardelo, 2004). Contudo, a profissionalização não garante o desvencilhamento de concepções sobre sua atuação, sustentadas no trabalho voluntário, sem definições e imerso numa equipe multiprofissional formada, prioritariamente, por profissionais de nível superior. Porém, a formação gera sentido emancipatório, valorização pessoal e social (Mota e David, 2010).

Conforme pesquisa na Carolina do Norte (EUA), é preciso sistematizar os aspectos ocupacionais do ACS. Vários estados focam na identificação das competências essenciais, em treinamentos e processos de certificação para o ACS, e alguns estados promulgaram legislação específica, com estratégias intersetoriais. Grupos de gestores de saúde recomendam: integrar o ACS aos sistemas de saúde, para aprimorar a competência cultural e compreensão da perspectiva do paciente; fortalecer sua conexão com as comunidades; desenvolver competências essenciais para a prática comunitária; examinar opções para a formação e a certificação, inclusive com parcerias com instituições de ensino superior; definir a remuneração; e medir a eficácia e o impacto da sistematização do trabalho do ACS (Nelson, Money Jr. e Petersen, 2016).

\section{Considerações finais}

Os ACSs estão presentes em diversos contextos geográficos e culturais, realizando ações que objetivam o cuidado à saúde da comunidade. Seguem orientações de acordo com cada sistema de saúde e demandas contextuais. Mas percebe-se a necessidade de clareza quanto às suas atribuições e respectiva execução. Tam- 
bém é preciso que haja mais esclarecimentos sobre as habilidades e competências demandadas pelo cuidado em saúde, associadas à inventividade, para que a saúde da comunidade seja seu foco. Receber formação propícia e ter acesso à educação permanente podem auxiliar o ACS na sua valorização na equipe e na sociedade, e o apoio financeiro e técnico é fundamental.

Contudo, tais recomendações podem se mostrar insuficientes para que o ACS seja verdadeiramente reconhecido e valorizado pelas equipes de saúde e pela sociedade. É imperiosa a necessidade de que os profissionais com nível superior tenham melhor formação durante a graduação e capacitação no trabalho, para promoção de mudança cultural, com valorização do ACS. Ressalta-se que o agente comunitário de saúde não deve ser considerado apenas um suporte para a realização de atividades na equipe, pois é profissional indispensável à reorientação da APS.

\section{Colaboradoras}

Jania Lurdes Pires Samudio foi responsável pela coleta de dados, método, resultado, discussão dos dados, conclusão, elaboração e redação do texto. Letícia Carneiro Brant e Ana Clara de Freitas Dias Costa Martins auxiliaram na coleta de dados; Maria Aparecida Vieira colaborou na análise dos dados, produção textual e revisão do conteúdo; Cristina Andrade Sampaio orientou toda a pesquisa e revisou o conteúdo do artigo.

Resumen Este estudio tuvo el objetivo avaluar, con la revisión integradora, el conocimiento producido en la literatura acerca de las actividades realizadas por los agentes comunitarios de salud en Brasil y otros países que disponen de dichos profesionales en su sistema de salud. La búsqueda de los datos abarcó: el Portal de Periódicos de la Coordinación de Perfeccionamiento del Personal de Nivel Superior; la biblioteca electrónica Scientific Electronic Library Online; Literatura de América Latina y el Caribe en Ciencias de la Salud; Análisis de Literatura Médica y recuperación del sistema en línea y la Biblioteca Nacional de Medicina de los Institutos Nacionales de Salud de Estados Unidos entre 2010 y 2014. De los 240 estudios identificados, 27 fueron incluídos en esta revisión. La literatura evidencia la variedad de funciones ejercidas por los agentes comunitarios de salud en diferentes contextos geográficos y culturales. El agente comunitario de salud tienen diversas formas de inserción en el mercado laboral, y vive fragilidades, oriundas de los contextos socioculturales de la comunidad, de la necesidad de mayor del sistema de salud y de las equipos. Su posición entre la comunidad y el equipo de salud es estratégica, lo que contribuye a la salud de la comunidad. Se debe posibilitarle formación adecuada a su trabajo y facilitar el acceso a la formación continua, factores que facilitan su mayor aprecio del equipo de salud y con la sociedad. Palavras-clave agente comunitario de salud; atención primaria de salud; políticas públicas; estrategia de salud de la familia. 


\section{Notas}

${ }^{1}$ Prefeitura de Montes Claros, Secretaria Municipal de Saúde, Montes Claros, Minas Gerais, Brasil.

<jansamudio@yahoo.com.br>

Correspondência: Prefeitura de Montes Claros, Nasf Santos Reis, Rua Marcos Ribeiro, 167, Santos Reis, CEP 39400-000, Montes Claros, Minas Gerais, Brasil.

${ }^{2}$ Universidade Estadual de Montes Claros, Montes Claros, Minas Gerais, Brasil.

<letletbrant@gmail.com>

${ }^{3}$ Universidade Estadual de Montes Claros, Montes Claros, Minas Gerais, Brasil.

$<$ anaclarafdcosta@hotmail.com>

${ }^{4}$ Universidade Estadual de Montes Claros, Departamento de Enfermagem, Montes Claros, Minas Gerais, Brasil.

$<$ di.vieira49@gmail.com>

${ }^{5}$ Universidade Estadual de Montes Claros, Departamento de Saúde Mental e Saúde Coletiva, Montes Claros, Minas Gerais, Brasil.

<cristina.sampaio@unimontes.br>

\section{Referencias}

AFULANI, Patience A. et al. Using community health workers in community-based growth promotion: what stakeholders think. Health Education Research, Oxford, v. 27, n. 6, p. 1.005-1.017, 2012.

ÁVILA, Maria M. M. O Programa de Agentes Comunitários de Saúde no Ceará: o caso de Uruburetama. Ciência \& Saúde Coletiva, Rio de Janeiro, v. 16, n. 1, p.349-360, 2011.

BORNSTEIN, Vera J.; STOTZ, Eduardo N. Concepções que integram a formação e o processo de trabalho dos agentes comunitários de saúde: uma revisão da literatura. Ciência \& Saúde Coletiva, Rio de Janeiro, v. 13, n. 1, p. 259-268, 2008.

BRASIL. Conselho Nacional de Educação. Parecer CEB: proposta de habilitação técnica para a profissão de agente comunitário de saúde. Brasília, 8 jul. 2004a. Disponível em: <http:// portal.mec.gov.br/cne/arquivos/pdf/CEB19. pdf $>$. Acesso em: 16 jul. 2017.
BRASIL. Perfil de competências profissionais do agente comunitário de saúde. Brasília: Ministério da Saúde, 2004b.

BRASIL. Portaria n. 648/GM, de 28 de março de 2006a. Aprova a Política Nacional de Atenção Básica, estabelecendo a revisão de diretrizes e normas para a organização da atenção básica para o Programa Saúde da Família (PSF) e o Programa Agentes Comunitários de Saúde (Pacs). Disponível em: $<$ http://dab.saude.gov.br/docs/legislacao/ portaria_648_28_03_2006.pdf $>$. Acesso em: 16 ago. 2015.

BRASIL. Lei n. 11.350, de 5 de outubro de 2006b. Regulamenta o $\S 5^{\circ}$ do art. 198 da Constituição, dispõe sobre o aproveitamento de pessoal amparado pelo parágrafo único do art. $2^{\circ}$ da emenda constitucional n. 51, de 14 fev. 2006, e dá outras providências. Disponível em: <http://www.planalto.gov. br/ccivil_03/_ato2004-2006/2006/lei/111350. htm>. Acesso em: 16 ago. 2015. 
BRASIL. Guia prático do agente comunitário de saúde. Brasília: Ministério da Saúde, 2009a.

BRASIL. O trabalho do agente comunitário de saúde. Brasília: Ministério da Saúde, 2009b.

BRASIL. Memórias da saúde da família no Brasil. Brasília: Ministério da Saúde, 2010.

BRASIL. Portaria n. 2.488, de 21 de outubro de 2011. Aprova a Política Nacional de Atenção Básica, estabelecendo a revisão de diretrizes e normas para a organização da atenção básica, para a Estratégia Saúde da Família (ESF) e o Programa de Agentes Comunitários de Saúde (Pacs). Disponível em: $<$ http://bvsms.saude.gov.br/bvs/saudelegis/ gm/2011/prt2488_21_10_2011.html>. Acesso em: 16 ago. 2015.

BRASIL. Lei n. 12.994, de 17 de junho de 2014. Altera a lei n. 11.350, de 5 de outubro de 2006, para instituir piso salarial profissional nacional e diretrizes para o plano de carreira dos agentes comunitários de saúde e dos agentes de combate às endemias. Disponível em: <http://www.planalto.gov.br/ ccivil_03/_ato2011-2014/2014/lei/112994. htm>. Acesso em: 16 ago. 2015.

BRASIL. Ministério do Trabalho. Portal do Trabalho e Emprego. Classificação Brasileira de Ocupações. 2015a. Disponível em: <http:// www.mtecbo.gov.br/cbosite/pages/pesquisas/ BuscaPorTituloResultado.jsf $>$. Acesso em: 16 ago. 2015.

BRASIL. Ministério da Saúde. Decreto n. 8.474, de 22 de junho de 2015b. Regulamenta o disposto no $\S 1^{\circ}$ do art. $9^{\circ}-\mathrm{C}$ e no $\S 1^{\circ}$ do art. $9^{\circ}$-D da lei n. 11.350 , de 5 de outubro de 2006, para dispor sobre as atividades de agente comunitário de saúde e de agente de combate às endemias. Disponível em: <http://www.planalto.gov.br/ ccivil_03/_ato2015-2018/2015/decreto/d8474. htm>. Acesso em: 16 ago. 2015.

BRAUN, Rebecca et al. Community health workers and mobile technology: a systematic review of the literature. Plos One, San Francisco, v. 8, n. 6, p. 1-12, 2013.
CAMPBELL, Jonathan D. et al. Community health worker home visits for Medicaid-enrolled children with asthma: effects on asthma outcomes and costs. American Journal of Public Health, Nova York, v. 105, n.11, p. 2.366-2.372, 2015.

CARDOSO, Andréia S.; NASCIMENTO, Marilene C. Comunicação no Programa Saúde da Família: o agente de saúde como elo integrador entre a equipe e a comunidade. Ciência \& Saúde Coletiva, Rio de Janeiro, v. 15, supl. 1, p. 1.509-1.520, 2010.

CARNEIRO, Carla C. G.; MARTINS, Maria I. C. Novos modelos de gestão do trabalho no setor público de saúde e o trabalho do agente comunitário de saúde. Trabalho, Educação e Saúde, Rio de Janeiro, v. 13, n. 1, p. 45-66, abr. 2015.

CAZOLA, Luiza H. O. et al. Incorporação das atividades de controle da dengue pelo agente comunitário de saúde. Revista de Saúde Pública, São Paulo, v. 48, n. 1, p. 113-122, 2014.

CECCIM, Ricardo B.; BRAVIN, Fábio P.; SANTOS, Alexandre A. Educação na saúde, saúde coletiva e ciências políticas: uma análise da formação e desenvolvimento para o Sistema Único de Saúde como política pública. Lugar Comum, Rio de Janeiro, v. 28, p. 159-180, 2011.

CORIOLANO, Maria W. L.; LIMA, Luciane S. Grupos focais com agentes comunitários de saúde: subsídios para entendimento destes atores sociais. Revista Enfermagem Uerj, Rio de Janeiro, v. 18, n. 1, p. 92-96, 2010.

COSTA, Simone M.; ARAÚJO, Flávia F. Auxiliares odontológicos contra agentes comunitários de saúde: semelhanças e contrastes. Revista de Odontologia da Unesp, Araraquara, v. 42, n. 5, p. 350-356, 2013.

COSTA, Simone M. et al. Agente comunitário de saúde: elemento nuclear das ações em saúde. Ciência \& Saúde Coletiva, Rio de Janeiro, v. 18, n. 7, p. 2.147-2.156, 2013.

CRISPIM, Juliane A. et al. Agente comunitário de saúde no controle da tuberculose na atenção primária à saúde. Acta Paulista de 
Enfermagem, São Paulo, v. 25, n. 5, p. 721727, 2012.

DANTAS, Dândara N. A. et al. Ações do agente comunitário de saúde no diagnóstico da tuberculose pulmonar. Revista da Rede de Enfermagem do Nordeste, Fortaleza, v. 12, n. esp., p. 980-994, 2011.

FERREIRA, Vitória S. C. et al. Processo de trabalho do agente comunitário de saúde e a reestruturação produtiva. Cadernos de Saúde Pública, Rio de Janeiro, v. 25, n. 4, p. 898-906, 2009.

FILGUEIRAS, Andréa S.; SILVA, Ana L. A. Agente comunitário de saúde: um novo ator no cenário da saúde do Brasil. Physis: Revista de Saúde Coletiva, Rio de Janeiro, v. 21, n. 3, p. 899-916, 2011.

FONSECA, Angélica F.; MOROSINI, Márcia V. G. C.; MENDONÇA, Maria H. M. Atenção primária à saúde e o perfil social do trabalhador comunitário em perspectiva histórica. Trabalho, Educação e Saúde, Rio de Janeiro, v. 11, n. 3, p. 525-552, 2013.

GIOVANELLA, Lígia; MENDONÇA, Maria H. M. Atenção primária à saúde. In: GIOVANELLA, Lígia et al. Políticas e sistema de saúde no Brasil. Rio de Janeiro: Editora Fiocruz, 2008. p. 575-625.

GOLNICK, Christine et al. Innovative primary care delivery in rural Alaska: a review of patient encounters seen by community health aides. International Journal of Circumpolar Health, v. 71, p. 1-10, 2012.

GOMES, Karine O. et al. O agente comunitário de saúde e a consolidação do Sistema Único de Saúde: reflexões contemporâneas. Physis: Revista de Saúde Coletiva, Rio de Janeiro, v. 20, n. 4, p. 1.143-1.164, 2010.

GUANAES-LORENZI, Carla; PINHEIRO, Ricardo L. Is the value of Community Healthcare Agents in Brazil's Family Health Strategy receiving full recognition? Ciência \& Saúde Coletiva, Rio de Janeiro, v. 21, n. 8, p. 2.537-2.546, 2016.
HAINES, Andy et al. Achieving child survival goals: potential contribution of community health workers. The Lancet, Londres, v. 369, n. 9.579, p. 2.121-2.131, 2007.

HARRIS, Matthew J.; HAINES, Andy. The potential contribution of community health workers to improving health ocoutcomes in UK primary care. Journal of the Royal Society of Medicine, Londres, v. 105, n. 8, p. 330-335, 2012.

HOLANDA-LAVOR, Antonio C. et al. Agente comunitário de saúde: um novo profissional para novas necessidades da saúde. Sanare, Sobral, v. 5, n. 1, p. 121-128, 2004.

JARDIM, Tatiana A.; LANCMAN, Selma. Aspectos subjetivos do morar e trabalhar na mesma comunidade: a realidade vivenciada pelo agente comunitário de saúde. Interface: Comunicação, Saúde e Educação, Botucatu, v. 13, n. 28, p. 123-135, 2009.

KEBIAN, Luciana V. A.; ACIOLI, Sônia. Visita domiciliar: espaço de práticas de cuidado do enfermeiro e do agente comunitário de saúde. Revista Enfermagem Uerj, Rio de Janeiro, v. 19, n. 3, p. 403-409, 2011.

KEBIAN, Luciana V. A.; ACIOLI, Sônia. A visita domiciliar de enfermeiros e agentes comunitários de saúde da Estratégia Saúde da Família. Revista Eletrônica de Enfermagem, Goiânia, v. 16, n. 1, p. 61-69, 2014.

LANDERS, Stewart; LEVINSON, Mira. Mounting evidence of the effectiveness and versatility of community health workers. American Journal of Public Health, Washington, v. 106, n. 4, p. 591-592, 2016.

LANZONI, Gabriela M. M.; CECHINEL, Caroline; MEIRELLES, Betina H. S. Agente comunitário de saúde: estratégias e consequências da sua rede de relações e interações. Revista da Rede de Enfermagem do Nordeste, Fortaleza, v. 15, n. 1, p. 123-131, 2014.

LEITE, André L. S.; PAULON, Simone. Atenção básica e desinstitucionalização da loucura: 
acionando competências dos agentes comunitários de saúde. In: PAULON, Simone; NEVES, Rosane. Saúde mental na atenção básica: a territorialização do cuidado. Porto Alegre: Sulina, 2013, p. 99-112.

LUNARDELO, Simone R. O trabalho do agente comunitário de saúde nos núcleos de saúde da família em Ribeirão Preto - São Paulo. 2004. 154 f. Dissertação (Mestrado em Enfermagem) - Escola de Enfermagem de Ribeirão Preto, Universidade de São Paulo, Ribeirão Preto, 2004.

MACIAZEKI-GOMES, Rita C. et al. The work of the community health worker from the perspective of popular health education: possibilities and challenges. Ciência \& Saúde Coletiva, Rio de Janeiro, v. 21, n. 5, p. 1.637-1.646, 2016.

MENDES, Eugênio V. O cuidado das condições crônicas na atenção primária à saúde: o imperativo da consolidação da Estratégia Saúde da Família. Brasília: Organização Pan-Americana da Saúde, 2012.

MENDES, Karina D. S. et al. Revisão integrativa: método de pesquisa para a incorporação de evidências na saúde e na enfermagem. Texto e Contexto Enfermagem, Florianópolis, v. 17, n. 4, p. 758-764, 2008.

MOBULA, Linda M. et al. Cultural competence and perceptions of community health workers' effectiveness for reducing health care disparities. Journal of Primary Care \& Community Health, Thousand Oakes CA, v. 6, n. 1, p. 10-15, 2015.

MOREIRA, Tatiana N. F. et al. A construção do cuidado: o atendimento às situações de violência doméstica por equipes de saúde da família. Saúde e Sociedade, São Paulo, v. 23, n. 3, p. 814-827, 2014.

MOROSINI, Márcia V. G. C. Educação e trabalho em disputa no SUS: a política de formação dos agentes comunitários de saúde. Rio de Janeiro: Escola Politécnica de Saúde Joaquim Venâncio, 2010.
MOTA, Roberta R. A.; DAVID, Helena M. S. L. A crescente escolarização do agente comunitário de saúde: uma indução do processo de trabalho? Trabalho, Educação e Saúde, Rio de Janeiro, v. 8, n. 2, p. 229-248, 2010.

NELSON, Sharon; MONEY JR., E. Benjamin; PETERSEN, Ruth. Community health workers: an integral part of an integrated health care team. North Carolina Medical Journal, Raleigh, v. 77, n. 2, p. 129-130, 2016.

NUNES, Mônica O. et al. O agente comunitário de saúde: construção da identidade desse personagem híbrido e polifônico. Cadernos de Saúde Pública, Rio de Janeiro, v. 18, n. 6, p. 1.639-1.646, 2002.

ODENDAAL, Willen A.; LEWIN, Simon. The provision of TB and HIV/Aids treatment support by lay health workers in South Africa: a time-and-motion study. Human Resources for Health, Bethesda MD, v. 12, n. 18, 2014.

PERRY, Henry. A brief history of community health worker programs. In: KIRCH, Wilhelm. (ed.). Encyclopedia of Public Health. Berlim: Springer, 2013. p.1-12.

PERRY, Henry; ZULLIGER, Rose. How effective are community health workers? Johns Hopkins Bloomberg School Public Health, 2012. Disponível em: <http://www.coregroup. org/storage/Program_Learning/Community_ Health_Workers/review\%20of\%20chw\%20 effectiveness $\% 20$ for $\% 20$ mdgs-sept2012.pdf $>$. Acesso em: 13 ago. 2015.

PICCININI, Carlos A.; NEVES, Rosane. A saúde bate à sua porta: olhares sobre a prática dos agentes comunitários de saúde. In: PAULON, Simone; NEVES, Rosane. Saúde mental na atenção básica: a territorialização do cuidado. Porto Alegre: Sulina, 2013, p. 83-98.

PINHEIRO, Ricardo L.; GUANAES-LORENZI, Carla. Funções do agente comunitário de saúde no trabalho com redes sociais. Estudos de Psicologia, Natal, v. 19, n. 1, p. 48-57, 2014. 
PINTO, Rogério M.; SILVA, Sueli B.; SORIANO, Rafael. Community health workers in Brazil's Unified Health System: a framework of their praxis and contributions to patient health behaviors. Social Science \& Medicine, Oxford, v. 74, n. 6, p. 940-947, 2012.

POLIT, Denise F.; BECK, Cheryl T.; HUNGLER, Bernadette P. Fundamentos de pesquisa em enfermagem. 5. ed. Porto Alegre: Artmed, 2011.

QUEIRÓS, Agleildes A. L. A prática dos agentes comunitários de saúde na América Latina: origem, contradições e desafios para o cuidado em saúde no começo do século XXI. 2015. 142 f. Tese (Doutorado em Saúde Pública) Universidade de São Paulo, São Paulo, 2015.

RAMOS, Marise N. Referências teórico-metodológicas da educação permanente em saúde no Brasil. Rio de Janeiro: Editora Fiocruz, 2006.

RHODES, Scott D. et al. A systematic community-based participatory approach to refining an evidence based community-level intervention: the HOLA intervention for Latino men who have sex with men. Health Promotion Practice, Illinois, v. 14, n. 4, p. 607-616, 2013.

RODRIGUES, Ana A. A. O.; SANTOS, Adriano M.; ASSIS, Marluce M. A. Agente comunitário de saúde: sujeito da prática em saúde bucal em Alagoinhas, Bahia. Ciência \& Saúde Coletiva, Rio de Janeiro, v. 15, n. 3, p. 907-915, 2010.

ROMAN, Lee A.; RAFFO, Jennifer E.; MEGHEA, Cristian I. Maternal perceptions of help from home visits by nurse-community health worker teams. American Journal of Public Health, Nova York, v. 102, n. 4, p. 643-645, 2012.

RUANO, Ana L. et al. 'It's the sense of responsibility that keeps you going': stories and experiences of participation from rural community health workers in Guatemala. Archives of Public Health, Bethesda MD, v. 70 , n. 18, p. 1-8, 2012.

SAKATA, Karen N.; MISHIMA, Silvana M. Articulação das ações e interação dos Agentes
Comunitários de Saúde na equipe de Saúde da Família. Revista da Escola de Enfermagem da USP, São Paulo, v. 46, n. 3, p. 665-672, 2012.

SANTOS, George A.; NUNES, Mônica O. O cuidado em saúde mental pelos agentes comunitários de saúde: o que aprendem em seu cotidiano de trabalho? Physis: Revista de Saúde Coletiva, Rio de Janeiro, v. 24, n. 1, p. 105-125, 2014.

SILVA, Elaine R. P. et al. Atuação dos agentes comunitários de saúde na Estratégia Saúde da Família. Cogitare Enfermagem, Curitiba, v. 17, n. 4, p. 635-641, 2012.

SILVA, Joana A.; DALMASO, Ana S. W. O agente comunitário de saúde e suas atribuições: os desafios para os processos de formação de recursos humanos em saúde. Interface: Comunicação Saúde e Educação, Botucatu, v. 6, n. 10, p. 75-83, 2002.

SIPS, Ilona et al. Community care workers, poor referral networks and consumption of personal resources in rural South Africa. Plos One, San Francisco CA, v. 9, n. 4, p. e95324, 2014.

SMITH, Deveridge A. S. et al. Task-shifting and prioritization: a situational analysis examining the role and experiences of community health workers in Malawi. Human Resources for Health, Bethesda MD, v. 12, n. 24,2014

TOMAZ, José B. C. O agente comunitário de saúde não deve ser um 'super-herói' . Interface: Comunicação Saúde e Educação, Botucatu, v. 6, n. 10, p. 75-94, 2002.

WALT, Gill. Community health workers in national programme: just another pair of hands? Philadelphia: Open University Press, 1990.

WITMER, Anne et al. Community health workers: integral members of the health care work force. American Journal of Public Health, Nova York, v. 85, n. 8, p. 1.055-1.058, 1995. 
WORLD HEALTH ORGANIZATION (WHO). Strengthening the performance of community health workers in primary health care: report of a WHO study group. Geneva: World Health Organization, 1989 (WHO Technical Report Series, n. 780). Disponível em: < http://apps. who.int/iris/bitstream/10665/39568/1/WHO_ TRS_780.pdf $>$. Acesso em: 15 ago. 2015.

WORLD HEALTH ORGANIZATION (WHO).

Community health workers: what do we know about them? Evidence and information for policy, Department of Human Resources for Health: Geneva, jan. 2007. Disponível em: <http://www.who.int/hrh/documents/ community_health_workers.pdf $>$. Acesso em: 13 ago. 2015.

Recebido em 10/05/2016

Aprovado em 26/10/2016 
